\title{
Fatty Acids as Therapeutic Auxiliaries for Oral and Parenteral Formulations
}

\author{
Michael J. Hackett ${ }^{\mathrm{a}}$, Jennica L. Zaro ${ }^{\mathrm{b}}$, Wei-Chiang Shen ${ }^{\mathrm{b}}$, Patrick C. Guley ${ }^{\mathrm{a}}$, and Moo J. \\ Cho ${ }^{a, f}$ \\ aUniversity of North Carolina - Chapel Hill, School of Pharmacy, Division of Molecular \\ Pharmaceutics \\ bUniversity of Southern California, School of Pharmacy, Division of Pharmaceutical Sciences
}

\begin{abstract}
Many drugs have decreased therapeutic activity due to issues with absorption, distribution, metabolism and excretion. The co-formulation or covalent attachment of drugs with fatty acids has demonstrated some capacity to overcome these issues by improving intestinal permeability, slowing clearance and binding serum proteins for selective tissue uptake and metabolism. For orally administered drugs, albeit at low level of availability, the presence of fatty acids and triglycerides in the intestinal lumen may promote intestinal uptake of small hydrophilic molecules. Small lipophilic drugs or acylated hydrophilic drugs also show increased lymphatic uptake and enhanced passive diffusional uptake. Fatty acid conjugation of small and large proteins or peptides have exhibited protracted plasma half-lives, site-specific delivery and sustained release upon parenteral administration. These improvements are most likely due to associations with lipidbinding serum proteins, namely albumin, LDL and HDL. These molecular interactions, although not fully characterized, could provide the ability of using the endogenous carrier systems for improving therapeutic outcomes.
\end{abstract}

\section{Supplementary Key Words}

Drug delivery; protein binding; endogenous drug carriers; albumin; drug absorption; drug formulation; fatty acids; triglycerides; lipid prodrugs; reversible lipidization

\section{Introduction}

\begin{abstract}
When a drug is absorbed or administered parenterally to an adult patient it is immediately diluted throughout 6 liters of blood and potentially $15 \mathrm{~L}$ of interstitial volume. The site of action for the drug will typically encompass only a very small fraction of total body volume so concentrations of drug at the target will be minimal. This dissipative nature of distribution poses a major problem for drug formulation leading to poor efficacy and high toxicity, particularly when drugs are hydrophobic and tend to distribute around the entire body. Being principally composed of water, the body has had to develop methods to promote the absorption and distribution of poorly soluble materials as they are critical for energy storage and membrane formation. Enterocytes in the lumen have specific fatty acid receptors to
\end{abstract}

\footnotetext{
‡corresponding author: 2309 Kerr Hall CB\# 7571, Chapel Hill, NC 27599, (919) 966-1345, mjcho@email.unc.edu.

Publisher's Disclaimer: This is a PDF file of an unedited manuscript that has been accepted for publication. As a service to our customers we are providing this early version of the manuscript. The manuscript will undergo copyediting, typesetting, and review of the resulting proof before it is published in its final citable form. Please note that during the production process errors may be discovered which could affect the content, and all legal disclaimers that apply to the journal pertain.
} 
facilitate uptake. The body also developed specific carriers to store lipid, LDL/HDL, and distribute fatty acids, albumin. Many investigators have then rationally designed prodrugs or formulations to utilize these systems for increasing solubility, promoting absorption, or facilitating distribution of their therapeutics. This review will focus on a subset of technologies utilizing fatty acids and triglycerides to improve the absorption, distribution, metabolism and excretion profiles for oral and parenteral administration. The use of medium-chain fatty acids for promoting intestinal permeation of hydrophilic drug molecules was the subject of an excellent review in 2009 [1] so only a cursory discussion is presented.

\section{Formulations to Improve Oral Absorption}

Ingested lipids are highly insoluble and thus aggregate as micelles or emulsions depending on composition. The presence of these lipids in the intestines triggers the release of lipases, phosphoplipases and bile salts designed to solubilize and hydrolyze triglycerides at the 1 and 3 positions to 2 -monoacylglycerides and free fatty acids. The fatty acids and glycerides can then partition into the membranes or bind fatty acid binding proteins on enterocytes for cellular uptake. Glycerides and long-chain fatty acids bind apical fatty acid binding proteins which deliver them to the endoplasmic reticulum (ER) of the enterocyte [2]. Shorter fatty acids, which exhibit higher solubility, can bind monocarboxylic acid transporters [3]. Shortand medium-chain fatty acids can be transported to the portal vein for first-pass transfer to the liver, presumably via albumin binding. Alternatively, long-chain fatty acids tend to be reacylated into triglycerides and incorporated in chylomicrons which are delivered to the lamina propria and eventually the systemic circulation via the thoracic duct [2]. Most of the triglycerides in chylomicrons are hydrolyzed by epithelial lipoprotein lipase and the chylomicron remnants eventually mature into very low-density lipoprotein (VLDL) then low-density lipoprotein (LDL) or high-density lipoprotein (HDL) if they contain a large quantity of phospholipids. Although its practical utility remains to be seen due to low level of availability, lymphatic uptake is a potentially useful mechanism for oral drug delivery to the systemic circulation as it bypasses the first pass clearance of the liver altogether.

\subsection{Caprates}

One method to promote paracellular diffusion of high solubility, low permeability molecules such as peptides is co-formulation with medium-chain fatty acids such as caprylates (C8:0) and caprates (C10:0). The mechanism of action for these fatty acids is not well established. Potentially the fatty acids modulate tight junctions through phospholipase $\mathrm{C}$ induced release of $\mathrm{Ca}^{2+}$ and subsequent protein kinase $\mathrm{C}$ activation [4,5]. Alternatively they may affect lipid rafts that anchor the occludin proteins [6] although it is unclear whether or not this is a caprate-specific effect as increased paracellular transport has been associated with a variety of fatty acids [7]. However, caprates specifically have been examined for increased paracellular diffusion in Caco-2 cell culture [8] as well as intact rat ileum via an Ussing chamber [9] and demonstrated up to a 7-fold increase in paracellular transit as well as occludin restructuring via immunohistochemistry. These fatty acids are considered non-toxic and have been used successfully in numerous formulations [1]. A series of basic studies have been streamlined for development through GIPET (Gastrointestinal Permeation Enhancement Technology) [10,11]. The technology involves formulating the drug along with caprate and caprylate salts in tablets and, to a lesser extent, enteric soft gel capsules. Application of the technology to low molecular weight heparin resulted in a doubling of the bioavailability in humans; however this number is still quite low at approximately $8 \%$. The relative bioavailability of oral acyline, a gonadotropin hormone releasing antagonist, increased up to 16-fold in beagles [1] and showed some activity in humans [12] despite a very modest total bioavailability. The addition of sodium caprate to a suppository containing ampicillin also showed a 2-fold increase in serum area under the curve in human volunteers although biopsy showed reversible damage to the mucosa [13]. The total absorption of these 
small and large molecules dose seem to increase consistently in the present of surfactants but the total increase may still be sub-optimal to translate into the clinic for most molecules. Of course, increased paracellular uptake to the portal vein is only half the issue as hepatic first-pass metabolism is sure to play a large role in clearance. Potentially then if the small molecules or peptides are being delivered to the liver this methodology could be effective enough to lead to a major pharmaceutical product.

\subsection{Triglyceride formulations}

Alternatively fatty acids can be used to elude first-pass metabolism by disguising a drug as a triglyceride. Valproic acid was esterified at the $s n-2$ position on the glycerol backbone of lysophosphatidylcholine [14]. This molecule showed an ability to absorb across the gut lumen of rats and get packaged into chylomicrons for distribution to the lymphatics. The drug, as this molecule is more active than valproic acid itself, was able to achieve 9\% bioavailability but $60 \%$ of absorption was due to lymphatic uptake. The drug showed great resistance to lipases in vitro although this was highly dependent on the chemistry involved in attaching the drug to the 2-position of glycerol. The bioavailability appears dependent on several other factors including the triglyceride vehicle and the pre/postprandial state; in both cases, the presence of other lipids. Formulation in peanut oil containing mostly palmitic (C16:0), stearic (C18:0), oleic (C18:1), and linoleic (C18:2) ester triglycerides promoted an increase in bioavailability. This is consistent with several other reports of small hydrophobic molecules formulated with long-chain triglycerides [15-17]. Alternatively, formulation with medium-chain triglycerides containing caprate and caprylate esters provided lower bioavailabilities. Interestingly the caprates and caprylates from the medium-chain triglyceride vehicle group don't appear to show any effect on bioavailability of the drug, yet $40 \%$ of the drug is estimated to be absorbed via the portal vein. Considering this the intact drug must be absorbed nearly exclusively transcellularly due to the poor solubility.

In addition to formulation with long-chain triglyceride, the postprandial state increased bioavailability compared with the starved state. Standard rat chow is about 3\% lipid, a vast majority of which are long-chain $\omega-3$ fatty acids [18]. In both successful scenarios the common denominator is the presence of long-chain fatty acids. This observation has been noted in several other reports on known lymphatically absorbed drugs as well [19-21]. Long-chain fatty acids have been associated with an increase in chylomicron formation in the Golgi apparatus of enterocytes [21] which could solubilize the hydrophobic drugs and promote increased lymphatic delivery. The increase in bioavailability via the lymphatics then is not very large. In general, the improvement in bioavailability of most hydrophobic drugs observed with concomitant administration of long-chain fatty acid seems to peak around 20\% including acylated aspirin [22], an acylated prodrug of L-Dopa [23] while even smaller increases are seen with hydrophobic drugs like lapatinib [24]. This is still impressive considering under normal conditions, the absorption of the natural hydrophobic molecule cholesterol is only about 50\% [25]. However these low bioavailabilities may only be acceptable for the most potent drugs. Just as with GIPET ${ }^{\circledR}$ It may be economically feasible to reduce the dose of drug while supplementing the formulation with long-chain fatty acid. Even from a nutritional standpoint this could be beneficial if the lipid contained $\omega-3$ or $\omega-6$ fatty acids and the possible benefits associated with them; particularly putatively lowering serum triglyceride levels [26]. This would require proving the $\omega-3$ and $\omega-6$ fatty acids still promoted increases in bioavailability and finding alternative sources of these fatty acids such as transgenic plants [27].

\subsection{Submicron lipid particles}

Submicron particles have been the subject of oral delivery recently due to their ability to carry a multitude of cargoes as well as their stability and targetability. Being too large for 
significant paracellular diffusion and lack of membrane permeability, these formulations require a different approach. The gastrointestinal tract is lined with a plethora of cells. M cells are associated with a great deal of lymphatic drainage due to their function of sampling antigen from the intestines and passing it to the various antigen presenting cells within the lymph [28]. M cells have a thin glycocalyx and undergo frequent macropinocytosis making them more amenable to taking up particles. It is hypothesized that intact particle uptake from the intestines may occur through $\mathrm{M}$ cells and enterocytes considering $\mathrm{M}$ cells are devoid of lysosomes [29]. Targeting to Peyer's Patches therefore could present an opportunity for increased lymphatic delivery of particles, particularly for inducing mucosal immunity for oral vaccines.

The common mucosal immune system is an autonomous system of immunity protecting various mucosal organs, most notably the airway, gut, eye and genitals [30]. It is estimated about $80 \%$ of immune-competent cells are involved in the common mucosal immune system which is designed to protect the vast area of mucosal organs thus preventing systemic infection. Lipid particles are commonly examined for use in vaccine delivery due to the nature of lymphatic uptake of lipids [29]. Formulation of antigen with cholera toxin in w/o/ w multiple emulsions containing squalene dispersed in saline with nonionic poloxamer surfactants allowed successful stabilization and delivery of a recombinant fusion protein from E. coli to Peyer's Patches [31] in mice. The fusion protein itself was unable to induce mucosal immunity subsequent to parenteral administration. In another preclinical study in guinea pigs, an orally viable tuberculosis vaccine was examined for mucosal immunization [32]. When formulated with vegetable oil, this strain of the mycobacterium was stabilized in the gastrointestinal tract for uptake. Formulation with vegetable oil improved the efficacy of the vaccine leading to greater protection when challenged with aerosolized tuberculosis compared to the standard subcutaneous vaccine. Despite this, there are no approved oral vaccines that are designed for epithelial adsorption although many are being developed. To this date only live attenuated or killed whole cell vaccines have been approved [33].

\section{Acylation of Therapeutic Molecules with Fatty Acids}

Pharmacokinetics and accompanied pharmacodynamics of parenterally administered drugs can be improved via acylation with various fatty acids. Lipidized therapeutics exhibit greater half-lives allowing less frequent dosing. This provides an alternative to the ubiquitous concept of pegylation for prolonging circulatory life. Being lipophilic, these therapeutics will most likely be solubilized by albumin or serum lipoproteins, both of which can contribute to stabilization and increased circulatory half-life. When unbound from proteins, the fatty acids can be removed based on chemistry due to $\mathrm{pH}$ or reductive glutathione as well as biochemical cleavage from peptidases or esterases. The chemistry is cost-effective, straightforward and the myriad of potential fatty acids allows tailoring of prodrugs for a specific purpose.

\subsection{Non-reversible lipidization}

In non-reversible methods of lipidization, peptide or proteins are typically modified with activated fatty acids (e.g., fatty acid chloride or anhydride) at the a-amino or the $\epsilon$-lysyl amino groups, resulting in a stable amide bond [34-37]. One example is the non-reversible lipidization of cystatin, a $13 \mathrm{kDa}$ protein isolated from chicken albumen that is a known inhibitor of cathepsin-B. Palmitoylation of the amino groups in this protein increased the membrane adsorptive or partitioning proclivity of the protein for endocytic internalization and subsequent inhibition of lysosomal cathepsin-B [38]. As expected, partitioning was dependent on the tail length of the fatty acid resulting in increased inhibition with increased tail length [39]. The maturation of the late endosome to lysosome would promote binding of the internalized cystatin molecules to cathepsins that are commonly found in these vesicles, 
assuming the palmitoylated protein survives the conditions of the lysosome. While successful in vitro, membrane adsorption is non-specific, so systemic administration would conceivably benefit from the use of a carrier such as a liposome or lipoprotein for targeted accumulation and release. Additionally, acylation could affect secondary or tertiary structures of proteins such that this is not a generally applicable method.

\subsection{Albumin binding}

The merits for binding albumin as a drug carrier are well established [40,41]. Albumin is a highly soluble protein which can confer solubility to hydrophobic drugs [42]. It has a 19-day half-life in humans [43] and it is extremely abundant at $40-50 \mathrm{mg} / \mathrm{mL}$ in the vasculature. It can thus greatly retard elimination from the system. While the primary function of albumin is plasma expansion, it is also a carrier for fatty acids [44]. Albumin has 6-7 fatty acid binding sites for long-chain fatty acids [45] with affinities in the nanomolar dissociation constant range [46]. The high affinity for the fatty acid binding sites is due to hydrophobic channels in the protein which cradle the aliphatic tail and cationic lysine or arginine residues at the apex of the channel which anchor the anionic carboxylate electrostatically [47,48]. The hydrophobic interactions within the binding pocket are primarily entropy-driven while the electrostatic interaction is both entropy and enthalpy-driven. Consequently, an attempt to utilize these pockets via fatty acid conjugation of a drug could disrupt the electrostatic interaction at the surface of albumin thereby decreasing the affinity.

To test this hypothesis, in an unpublished study, a drug surrogate fluoresceinamine (FLA) was derivatized with a short diethyleneglycol linker. The surrogate was subsequently attached to stearic acid (SA) and 3-pentadecylglutaric (PDG) acid via an amide as shown in Fig. 1. The only difference between the two molecules is the carboxymethyl moiety on the PDG acid which is hypothesized to anchor the conjugate to the protein. Both conjugates were subject to isothermal titration calorimetry analysis at $30^{\circ} \mathrm{C}$, from which the binding parameters could be extracted. The results show a 3.5 -fold increase in affinity of PDG-FLA for delipidated human serum albumin. This is derived from greater than twofold increase in enthalpy for the PDG conjugate compared to the SA conjugate. Interestingly the SA-FLA conjugate does show 1.5-fold higher entropy compared to the PDG conjugate. This could be a result of the carboxymethyl group on PDG preventing the proper seating of the conjugate in the binding pocket. While studies to examine this effect are ongoing, the data is presented as it seemingly confirms other data in the literature, specifically the increase in affinity observed by acylating insulin.

The seminal use of fatty acids for this purpose was myristoylated insulin detemir (Levemir ${ }^{\circledR}$, Novo Nordisk, Denmark), which was approved by the FDA in 2005. Insulin is a $5.8 \mathrm{kDa}$ polypeptide consisting of two chains linked by three disulfides. In Levemir ${ }^{\circledR}$, the polypeptide is myristoylated at the penultimate lysine residue (B29) [49]. Intact insulin polypeptide is terminated with threonine (B30); however in Levemir ${ }^{\circledR}$ the terminal threonine is removed. It was found removal of the terminal threonine increased the affinity of Levemir $^{\circledR}$ for albumin by approximately 3 -fold, similar to the fluoresceinamine conjugate above [50]. The reason for this change in affinity is most likely due to how the molecule fits in the albumin binding pocket. It is presumed the myristoyl amide as well as the whole lysine side chain fit in the pocket [50]. If true, the binding pocket would accommodate 20 atoms from the $\omega$-position of the myristic acid to the a-carbon branching point of lysine. Assuming the amide does not perturb binding in the pocket, this distance would be comparable to arachadic acid (C20:0) which is known to bind albumin [51]. Therefore in detemir, the $C$-terminus of the lysine likely sits atop the pocket for electrostatic interactions with the cationic lysine or arginine on albumin. If threonine is not cleaved, as with native insulin, the $C$-terminal carboxyl group would shift one amino acid away from the binding pocket making formation of the salt-bridge less likely. The result of this higher affinity 
albumin conjugate is an increase in the half-life of insulin from $2.8 \mathrm{~h}$ to $8.8 \mathrm{~h}$ and no loss of activity when administered subcutaneously $[49,52]$.

More recently, a second lipidized peptide drug, liraglutide (Victoza ${ }^{\circledR}$, Novo Nordisk), was also approved by the FDA in 2010 [53]. Victoza ${ }^{\circledR}$ is an analog of glucagon-like peptide (GLP-1), a 37-amino acid native peptide hormone that has a short pharmacological half-life of about $1 \mathrm{~h}$. Victoza ${ }^{\circledR}$ differs from GLP-1 in the substitution of Lys34 to Arg34, and in the palmitoylation at Lys 26 via a Y-glutamic acid spacer. This modification results an improved pharmacokinetic profile, which is attributed to albumin-binding of liraglutide following administration. Due to the long half-life of $11-15 \mathrm{~h}$ following subcutaneous injection, this lipidized analog is suitable for once-daily injection. Another insulin analog, insulin degludec, is also in development by Novo Nordisk. Similar to Victoza ${ }^{\circledR}$, insulin degludec is palmitoylated at an $\epsilon$-lysyl amino group (B29) via a $Y$-glutamic acid spacer, and also has the terminal threonine removed. Promising results from phase II clinical trials of insulin degludec have shown that subcutaneous administration three times a week produced glycemic control comparable to insulin glargine, an FDA approved long-acting basal insulin analogue in patients with Type I [54] and Type II diabetes [55].

\subsection{Reversible lipidization}

The non-reversible lipidization of protein or peptide drugs has some limitations including the incompatibility between lipidization reagents and proteins/peptides in solution, and the loss of biological activity of the protein or peptide drug following modification. One technology to promote the half-life of the protein as well as maintain activity is reversible aqueous lipidization (REAL technology) [56]. This methodology involves the use of watersoluble acylation reagents thus circumventing the requirement of organic solvents used in non-reversible lipidization. Additionally, in vivo reversible bonds (e.g. disulfide or $\mathrm{pH}$ sensitive bonds) are utilized to link the lipid moiety to the protein or peptide allowing regeneration of free protein or peptide following administration. In this prodrug approach the disulfide bonds between cysteine residues in the protein are reduced, and the resultant free thiols are reacted with an activated disulfide of palmitoylated cysteine [57]. The weakly reducing conditions of the serum can then slowly delipidate the modified protein allowing refolding and providing a controlled release of intact, bioactive protein. Reversible lipidization using a $\mathrm{pH}$-sensitive linkage involves the modification of free amino groups on the protein using an amine-reactive lipidization reagent. The free protein is then slowly regenerated in vivo by hydrolysis at physiological $\mathrm{pH}$ [58].

REAL technology has been applied to both peptides and proteins demonstrating increases in half-life as summarized in Table 1. When applied to $\mathrm{Tyr}^{3}$-octreotide (TOC), a $\sim 1 \mathrm{kDa}$ somatostatin analog for controlled delivery to the liver [59], the half-life of ${ }^{125}$ I-labeled TOC and REAL-TOC increased from $4.2 \mathrm{~h}$ to $6.6 \mathrm{~h}$ [59]. When REAL was applied to the diuretic desmopressin $(\sim 1 \mathrm{kDa})$ [60], an increase in stability, potency and half-life was observed [61]. Similar improvements in pharmacokinetics, stability, and bioactivity have been observed for other proteins and peptides, including enkephalin $(\sim 0.5 \mathrm{kDa})$ [58], calcitonin ( 3.4 kDa) [62], interferon alpha ( 20 kDa) [63] and Bowman-Birk protease inhibitor $(\sim 8 \mathrm{kDa})$ [64]. These benefits are most likely the result of binding to serum albumin. Similar to insulin detemir where palmitoylation is occurring through an amide of a terminal amino acid, the carboxylate on cysteine should be readily available for fulfilling the electrostatic interaction involved in albumin binding. In support of this hypothesis, changing the REAL technology's cysteine to cysteamine by decarboxylation or masking the charge with a methyl ester caused drastic decreases in the efficacy of the drug [65]. Both modifications would eliminate the electrostatic interaction thus disrupting the high-affinity nature of albumin binding. 
In addition to the improved stability and pharmacokinetic profile, both reversible and irreversible lipidization techniques have been utilized as an approach to facilitate the oral delivery of protein and peptide drugs. Although there are many reports on the oral administration of lipidized peptides, including insulin [66], tetragastrin [67], DADLE [68], calcitonin [62], and enkephalin [58], none of them has been further developed into an advanced development stage. One of the limitations of using lipidized peptides for oral delivery is the lack of a systematic study of the mechanism of enhanced oral absorption. In addition, there are many factors, such as the linker used in lipid-conjugation, the formulations for oral administration, and the presence of other excipients that can influence the oral bioavailability of a lipidized peptide [67-70]. Nevertheless, all of the studies have shown that, compared to unmodified peptide, the lipidized peptidyl drugs exhibited improvements in the pharmacological activity as well as an increased mucosal permeability, plasma concentration, and area under the curve (AUC). Therefore, lipidization can be considered as an alternative approach in oral protein or peptide delivery but not a solution to the underlying issues in absorption [71-73].

\section{Lipoproteins as Carriers}

Aside from albumin, the other major family of natural lipid carriers is the lipoproteins. Lipoproteins are particles formed by the aggregation of triglycerides, phospholipids, cholesterol and cholesteryl ester. The whole complex is stabilized by a massive apolipoprotein. The LDL molecule has been modeled very thoroughly. It is believed to be a discoid particle (Fig. 2) [74] consisting of 40\% cholesteryl ester, 9\% free cholesterol, 25\% phospholipid, $7 \%$ triglyceride and $21 \%$ protein by mass [75]. The particles differ by composition, size and stabilizing proteins yielding several classes; chylomicrons, VLDL, intermediate density lipoprotein (IDL), LDL and HDL [76,77]. Primarily, VLDL/LDL/HDL are used as drug carriers. VLDL receptors are commonly expressed in the capillary endothelium of muscle, heart and adipose tissues while LDL receptors tend to be expressed highly in the liver as well as many tumor tissues [76,78]. HDL is also cleared primarily by the liver using the scavenger receptor SRB1 but is also heavily consumed by various cancerous cells [79]. The particles are stable with biological half-lives of several days, as well as an assumed protection from reticuloendothelial clearance [76,80]. Lipoproteins provide competition for the binding of fatty acid substrates with albumin with comparable delivery potentials [81], although how long the complex remains intact in vivo is not clearly understood. The triglyceride on the surface is available for hydrolysis, as was the case with chylomicrons, so ideally the drugs will partition to the core of the LDL which is typically reserved for cholesteryl ester. To do so, the drug will likely have to be very insoluble. This would make the drug easier to control and it would likely be taken up in tissues containing the highest levels of LDL receptor which could be particularly useful in cancer treatment.

\subsection{Lipoproteins in gene delivery}

In an exemplary study using various acylated siRNAs, it was found cholesterol and longchain fatty acid, including stearic and behenic (C22:0) acid, conjugated siRNAs show preferential binding to lipoproteins. Conversely, myristoylated, palmitoylated and oleoylated siRNA bind exclusively to albumin [82]. The behenic and stearic derivatives bound HDL/ LDL with "dissociation constants" of $100 \mu \mathrm{M}$ and $300 \mu \mathrm{M}$, respectively. The affinity was estimated by the ratio of bound/unbound cholesterol siRNA at given concentrations of lipoprotein. Rather than a dissociation constant, this may be better described as a partition coefficient as there is no specific binding site provided by the lipid aggregates but rather a propensity to partition into the particle. This can be further confounded by the significant variability in composition of natural lipoprotein particles as opposed to the well characterized structure of albumin. The behenic and stearic derivatives bound albumin with dissociation constants of approximately $200 \mu \mathrm{M}$ and saturated the protein at 3.6 molar 
equivalents. These values are in stark contrast to the free fatty acids which bind in the low nanomolar dissociation range with $\sim 6$ binding sites for stearic acid and 4 for behenic acid [46,51]. Here again, the acylation chemistry eliminates the carboxylate moiety of all fatty acids so albumin binding is expected to decrease. In this instance the loss of affinity is several orders of magnitude. This large decrease may also be due to the size and hydrophilic nature of the attached nucleic acid coupled with the electrostatic repulsion between the phosphodiester backbone and the anionic surface of albumin.

A major concern for these complexes is in vivo stability. The higher the "affinity", the more the drug's pharmacokinetics should mimic that of the carriers themselves. These proteins are all catabolized throughout the body and hence the respective ratio of catabolism in various tissues is also important in terms of both efficacy and toxicity. The steady-state accumulation rates and degradation profiles for these carriers are well understood and consistent. This raises the question, can drug conjugates be designed to utilize these carriers for protracted serum half-life? To examine this, the investigators analyzed the pharmacokinetics of a cholesterol conjugate of siRNA (Fig. 3) in mice using a dual label following intravenous administration; ${ }^{125} \mathrm{I}$ on the carrier (LDL, HDL, or albumin) and ${ }^{32} \mathrm{P}$ on the cholesterol siRNA. All three carriers exhibited their natural half-lives whereas the siRNA conjugates were completely cleared from the vasculature within 5 hours clearly reflecting the relatively weak association of the conjugates for the carriers. This is undesirable as the conjugates are not effectively utilizing the potential of the carriers' increased circulatory half-life due to weak interactions with the carriers; the very hydrophilic siRNA is incompatible with the lipophilic LDL/HDL carrier and the cholesterol ligand is incompatible with albumin due to very weak binding interactions. As a result, the weakly bound conjugates cannot be expected to take advantage of the differential tissue accumulation of these carriers for selective tissue delivery. Designing conjugates with increased specificity, affinity and compatibility for the respective carriers could allow for better efficacy profiles.

\subsection{HDL as a drug carrier for cancer}

Delivery via HDL has recently focused on cancerous cells. The carriers used are recombinant, formed by suspending triglycerides with bacterially expressed Apolipoprotein A1 (Apo-A1) followed by heating and sonication [83]. The advent of Apo-A1 fusion proteins delineated two possibilities; the fusion protein could be therapeutic or, since the Apo-A1 sits at the interface, the fusion protein could include a targeting peptide [84]. In one instance, interleukin-11a was selected as a targeting peptide as the receptor is highly expressed in various cancer cell lines $[85,86]$. These particles showed selective targeting to osteosarcoma masses and the addition of a cytotoxic peptide demonstrated efficacy in vitro. Efficacy was also demonstrated in mice by fusing the cell penetrating TAT peptide from the human immunodeficiency virus to Apo-A1 carrying unmodified doxorubicin in the particle and administering intravenously [84]. The particles release about $40 \%$ of the encapsulated doxorubicin within $5 \mathrm{~h}$ in normal saline containing $0.1 \%$ bovine serum albumin. Intratumoral injection of the recombinant rHDL showed efficacy of about $30 \%$ reduced tumor volume compared to the untreated control. The results were comparable regardless of the presence of the TAT peptide or the rHDL itself, as free doxorubicin had comparable efficacy. Considering the release rate, most of the doxorubicin is probably released quickly into the tumor. To prevent this leakage or dissociation, the doxorubicin could be acylated, which would greatly increase the permeability into rHDL. Here again $\omega-3$ fatty acids, such as docosahexaeoic acid and linolenic acid, could be used as these not only promote membrane permeability but are hypothesized to increase sensitization in a variety of tumor cells [87-89]. A similar approach involved using a recombinant Apo-A1 $1_{\text {Milano }}$ mutant with higher affinity for the HDL receptor [90]. These particles were loaded with 10- 
hydroxycamptothecin at up to $80 \%$ efficiency and showed a controlled release of $25 \%$ of the dose over $24 \mathrm{~h}$ when dialyzed in buffer. Biodistribution in naïve mice shows primarily uptake in the kidneys and to a lesser extent the liver and spleen. Biodistribution was not yet performed on tumor bearing mice at the time of this writing.

\subsection{LDL as a drug carrier for cancer}

As with HDL, small synthetic LDL particles have been developed. Coined "nano-LDL", the synthetic lipoprotein combines a peptide fragment that binds the LDL receptor anchored to the particle via a lipid for the purpose of targeting cancerous cells; specifically glioblastoma multiforme [91]. The particle was formed with phospholipids and triglycerides as well as an oleic acid derivative of paclitaxel [92] which mimics the cholesteryl ester. The nano-LDL was able to solubilize the paclitaxel prodrug at $0.33 \mathrm{mg} / \mathrm{mL}$ ( $6 \%$ of total mass) and was shown to be very toxic to multiple glioblastoma multiforme cell lines expressing variable amounts of the LDL receptor. It is suggested most neurons do not express high levels of the LDL receptor, which could make this vehicle highly selective for glioblastoma multiforme cells in the brain. The difficulty for LDL to cross the blood-brain barrier coupled with the ubiquitous expression of the LDL receptor systemically will preclude the use of this approach for parenteral administration. The quantity of drug that can be stored in these particles is low, $6 \%$, compared with the $40 \%$ composition of cholesteryl ester in LDL. However the overexpression of LDL receptors in many different tumors could make this particle very useful for the treatment of a variety of systemic tumors. The largest issue here would be the synthesis of large scale quantities of nano-LDL as well as its potentially short shelf-life. Without the full Apo-B100 protein, the emulsion itself may be too unstable for storage although the issue of stability was never mentioned.

\subsection{LDL as a drug carrier for atherosclerosis}

Aside from cancer, LDL is often associated with atherosclerosis. An excess of oxidized LDL, due to high concentrations of blood-borne lipid and cholesterol, leads to consumption in aortic vasculature by macrophages transforming them into foam cells [93]. Over time, more macrophages are attracted and the vasculature becomes congested and the excess cholesterol forms plaques. Oxidized LDL may bind these plaques more tightly than native LDL facilitating undesirable accumulation of the lipoprotein [94] although this appears to decrease with progression of the disease. This spontaneous accumulation of LDL at the target site makes it an ideal carrier for a therapeutic [95]. The steroid dexamethasone has been shown to prevent transformation into foam cells. Palmitoyl dexamethasone was then partitioned into human LDL collected by ultracentrifugation from serum. Biodistribution in atherosclerotic mice following intravenous injection showed a decrease in distribution to the liver and increase to the target site, the aorta [96]. Accumulation persisted for 7 days and successfully protected early atherosclerotic lesions from worsening, however it did not affect the underlying dyslipidemia. Due to the difficulty in isolating large quantities of human LDL, the potential for transferring blood-borne pathogens and variability in particles, native LDL may be a difficult vehicle to use systemically [92]. The ex vivo synthesis of LDL using recombinant Apo-B100 could be promising, but only on a very small scale due to difficulty isolating significant amounts of protein. Synthetic LDL-like emulsions, as in the case nano-LDL, may prove the most efficient for development [92,97] if they can be stabilized and incorporate larger quantities of drug.

\section{Concluding Remarks and Future Directions}

For parenteral administration, drug development has begun to focus on drug delivery which has recently become synonymous with nanotechnology. The focus is on the development of drug carriers with long circulatory lives that may render targeted delivery feasible. There 
have been some major accomplishments in the field such as the FDA approval of liposomal doxorubicin, Doxil ${ }^{\circledR}$ and the approval of albumin-paclitaxel particle Abraxane ${ }^{\circledR}$. Both formulations are more efficacious than free drug, however Doxil ${ }^{\circledR}$ is not primarily indicated as a stand-alone therapy while Abraxane ${ }^{\circledR}$, outside of ovarian cancer, is only primarily indicated in combination therapy. The significantly higher cost of these formulations is partly responsible for their indications. The high cost is likely derived from difficulty in scaling up production and minimizing batch to batch variability. The infrastructure exists to scale up synthesis of specific chemical entities, but nanotechnology involves additional formulation; e.g. reconstitution and remote loading of liposomes or the aggregation of purified serum albumin with paclitaxel. These extra excipients and specialized manufacturing can be costly and dilute the drug/carrier ratio. Additionally by virtue of being synthetic, these carriers have inherent issues. Despite being made of biologically-inert materials, nanocarriers are not inherently biologically-compatible in that many formulations are seen as foreign and cleared by the RES. Methods such as PEGylation have been implemented to slow RES clearance, however this has been shown to lead to even faster clearance of liposomes upon subsequent injections through accelerated blood clearance (ABC) kinetics [98]. The mechanism for this is potentially an immune reaction to PEGlipids which tends to be weak for IgG but strong for IgM [99]. As expected, it is difficult to impose tolerance on a biological system predicated on being intolerant to foreign bodies. One alternative is to start with carriers the body already tolerates.

The human body takes in a variety of essential nutrients from gases to solids, large to small, hydrophobic to hydrophilic. These nutrients need to be transported throughout the body and thus endogenous carriers were evolved that are selective, efficient and biologically compatible. This selectivity can offer a great service in the field of drug delivery [100]. Erythrocytes carry oxygen and have a life span of 120 days [101]; hypotonic loading of these cells with therapeutic proteins can allow controlled serum release [102]. Monocytes travel to sites of inflammation and even traverse the BBB, as such they are being examined as carriers for gene transfer in the brain [103]. On a sub-cellular scale are the nutrient carriers; albumin for fatty acids, lipoproteins for triglycerides and cholesterol, and transferrin for iron. In the case of the albumin binding insulin detemir the modification is purely chemical, and only a single step so the infrastructure for scale-up of this product is already present in the industry. Because of the simplicity the cost-effectiveness is comparable to the recombinant basal insulin glargine [104]. This methodology has worked well for three peptides in diabetes so conceivably the methodology could be expanded into controlled release of peptides for other indications. However, as a targeted drug carrier, albumin and the lipoproteins may be better suited for delivery to cancerous tissues [76].

Both albumin and lipoproteins have been observed to accumulate and degrade readily in many human tumors $[105,106]$. This is not surprising because rapidly dividing cells will need a great deal of lipid and energy for expansion and division. The use of native albumin for cytotoxic delivery of doxorubicin is in clinical development [107] with preclinical evaluation being examined for several other drugs $[108,109]$. Theoretically then, acylation of cancer drugs for albumin binding or LDL incorporation could also result in simple but cost-effective improvements to treatments as well. A major concern for using protein complexation is the stability of the complex in vivo. Most every, especially water-insouble, drug binds albumin due to its relative abundance, but dissociation of these molecules is expected to rapid compared to the dissociation of tightly bound fatty acids. Therefore if the complexation is strong enough, selective albumin binding could be a general method to reduce the toxicity of cytotoxic agents. While targeted drug delivery has been a major focus in nanotechnology in recent decades, it is important to reflect that nature has been designing drug carriers for millennia. 


\section{Acknowledgments}

We would like to thank Jae Aoh and Jason Whitley for their work on the table of content image and Fig. 1 respectively. We would also like to thank David Needham, $\mathrm{PhD}$, Duke University for discussions on the various topics presented.

\section{References}

1. Maher S, Leonard TW, Jacobsen J, Brayden DJ. Safety and efficacy of sodium caprate in promoting oral drug absorption: from in vitro to the clinic. Adv. Drug Deliv. Rev. 2009; 61:1427-1449. [PubMed: 19800376]

2. Mansbach CM, Siddiqi SA. The biogenesis of chylomicrons. Annu. Rev. Physiol. 2010; 72:315333. [PubMed: 20148678]

3. Thwaites DT, Anderson CMH. H+-coupled nutrient, micronutrient and drug transporters in the mammalian small intestine. Exp. Physiol. 2007; 92:603-619. [PubMed: 17468205]

4. Lindmark T, Kimura Y, Artursson P. Absorption enhancement through intracellular regulation of tight junction permeability by medium chain fatty acids in Caco- 2 cells. J. Pharmacol. Exp. Ther. 1998; 284:362-369. [PubMed: 9435199]

5. Soboll S, Gründel S, Schwabe U, Scholz R. Influence of fatty acids on energy metabolism 2 Kinetics of changes in metabolic rates and changes in subcellular adenine nucleotide contents and $\mathrm{pH}$ gradients following addition of octanoate and oleate in perfused rat liver. Eur. J. Biochem. 1984; 141:231-236. [PubMed: 6723661]

6. Sugibayashi K, Onuki Y, Takayama K. Displacement of tight junction proteins from detergentresistant membrane domains by treatment with sodium caprate. Eur J Pharm Sci. 2009; 36:246-253. [PubMed: 19013238]

7. Ilbäck N-G, Nyblom M, Carlfors J, Fagerlund-Aspenström B, Tavelin S, Glynn AW. Do surfaceactive lipids in food increase the intestinal permeability to toxic substances and allergenic agents? Medical Hypotheses. 2004; 63:724-730. [PubMed: 15325024]

8. Anderberg EK, Lindmark T, Artursson P. Sodium caprate elicits dilatations in human intestinal tight junctions and enhances drug absorption by the paracellular route. Pharm. Res. 1993; 10:857-864. [PubMed: 8321854]

9. Soderholm JD, Oman H, Blomquist L, Veen J, Lindmark T, Olaison G. Reversible increase in tight junction permeability to macromolecules in rat ileal mucosa in vitro by sodium caprate, a constituent of milk fat, digestive diseases and sciences. 1998; 43:1547-1552.

10. Leonard TW, Lynch J, McKenna MJ, Brayden DJ. Promoting absorption of drugs in humans using medium-chain fatty acid-based solid dosage forms: GIPET. Expert Opin Drug Deliv. 2006; 3:685692. [PubMed: 16948563]

11. Walsh EG, Adamczyk BE, Chalasani KB, Maher S, O’Toole EB, Fox JS, Leonard TW, Brayden DJ. Oral delivery of macromolecules: rationale underpinning Gastrointestinal Permeation Enhancement Technology $\left(\right.$ GIPET $\left.^{\circledR}\right)$. Therapeutic Delivery. 2011; 2:1595-1610. [PubMed: 22833984]

12. Amory JK, Leonard TW, Page ST, O'Toole E, McKenna MJ, Bremner WJ. Oral administration of the GnRH antagonist acyline, in a GIPET ${ }^{\circledR}$-enhanced tablet form, acutely suppresses serum testosterone in normal men: single-dose pharmacokinetics and pharmacodynamics. Cancer Chemother Pharmacol. 2009; 64:641-645. [PubMed: 19479252]

13. Lindmark T, Söderholm JD, Olaison G, Alván G, Ocklind G, Artursson P. Mechanism of Absorption Enhancement in Humans After Rectal Administration of Ampicillin in Suppositories Containing Sodium Caprate. Pharmaceutical Research. 1997; 14:930-935. [PubMed: 9244152]

14. Dahan A, Duvdevani R, Shapiro I, Elmann A, Finkelstein E, Hoffman A. The oral absorption of phospholipid prodrugs: in vivo and in vitro mechanistic investigation of trafficking of a lecithinvalproic acid conjugate following oral administration. J Control Release. 2008; 126:1-9. [PubMed: 18082281]

15. Faisal W, O'Driscoll CM, Griffin BT. Bioavailability of lycopene in the rat: the role of intestinal lymphatic transport. J. Pharm. Pharmacol. 2010; 62:323-331. [PubMed: 20487215] 
16. Han S, Yao T, Zhang X, Gan L, Zhu C, Yu H, Gan Y. Lipid-based formulations to enhance oral bioavailability of the poorly water-soluble drug anethol trithione: effects of lipid composition and formulation. Int J Pharm. 2009; 379:18-24. [PubMed: 19508887]

17. Porter CJH, Kaukonen AM, Taillardat-Bertschinger A, Boyd BJ, O'Connor JM, Edwards GA, Charman WN. Use of in vitro lipid digestion data to explain the in vivo performance of triglyceride-based oral lipid formulations of poorly water-soluble drugs: studies with halofantrine. J Pharm Sci. 2004; 93:1110-1121. [PubMed: 15067688]

18. Langley-Evans SC, Clamp AG, Grimble RF, Jackson AA. Influence of dietary fats upon systolic blood pressure in the rat. Int J Food Sci Nutr. 1996; 47:417-425. [PubMed: 8889627]

19. Caliph SM, Faassen WAF, Vogel GM, Porter CJH. Oral bioavailability assessment and intestinal lymphatic transport of Org 45697 and Org 46035, two highly lipophilic novel immunomodulator analogues. Curr Drug Deliv. 2009; 6:359-366. [PubMed: 19534711]

20. Trevaskis NL, McEvoy CL, McIntosh MP, Edwards GA, Shanker RM, Charman WN, Porter CJH. The role of the intestinal lymphatics in the absorption of two highly lipophilic cholesterol ester transfer protein inhibitors (CP524,515 and CP532,623). Pharm. Res. 2010; 27:878-893. [PubMed: 20221896]

21. Ghoshal S, Witta J, Zhong J, de Villiers W, Eckhardt E. Chylomicrons promote intestinal absorption of lipopolysaccharides. Journal of Lipid Research. 2009; 50:90-97. [PubMed: 18815435]

22. Kumar R, Billimoria JD. Gastric ulceration and the concentration of salicylate in plasma in rats after administration of 14C-labelled aspirin and its synthetic triglyceride, 1,3-dipalmitoyl-2(2'acetoxy-[14C]carboxylbenzoyl) glycerol. J. Pharm. Pharmacol. 1978; 30:754-758. [PubMed: 32238]

23. Garzon-Aburbeh A, Poupaert JH, Claesen M, Dumont P. A lymphotropic prodrug of L-dopa: synthesis, pharmacological properties and pharmacokinetic behavior of 1,3-dihexadecanoyl-2[(S)-2-amino-3-(3,4-dihydroxyphenyl)propanoyl]propane-1,2,3-triol. J. Med. Chem. 1986; 29:687-691. [PubMed: 3084786]

24. Koch KM, Reddy NJ, Cohen RB, Lewis NL, Whitehead B, Mackay K, Stead A, Beelen AP, Lewis LD. Effects of Food on the Relative Bioavailability of Lapatinib in Cancer Patients. JCO. 2009; 27:1191-1196.

25. Bosner MS, Lange LG, Stenson WF, Ostlund RE Jr. Percent cholesterol absorption in normal women and men quantified with dual stable isotopic tracers and negative ion mass spectrometry. $\mathrm{J}$. Lipid Res. 1999; 40:302-308. [PubMed: 9925660]

26. Samuel S, Peskin B, Arondekar B, Alperin P, Johnson S, Blumenfeld I, Stone G, Jacobson TA. Estimating health and economic benefits from using prescription omega-3 fatty acids in patients with severe hypertriglyceridemia. Am. J. Cardiol. 2011; 108:691-697. [PubMed: 21840433]

27. Miller MR, Nichols PD, Carter CG. n-3 Oil sources for use in aquaculture--alternatives to the unsustainable harvest of wild fish. Nutr Res Rev. 2008; 21:85-96. [PubMed: 19087364]

28. Clark MA, Jepson MA, Hirst BH. Exploiting M cells for drug and vaccine delivery. Advanced Drug Delivery Reviews. 2001; 50:81-106. [PubMed: 11489335]

29. Hussain N, Jaitley V, Florence AT. Recent advances in the understanding of uptake of microparticulates across the gastrointestinal lymphatics. Adv. Drug Deliv. Rev. 2001; 50:107-142. [PubMed: 11489336]

30. Holmgren J, Czerkinsky C. Mucosal immunity and vaccines. Nat Med. 2005

31. Tomasi M, Dertzbaugh MT, Hearn T, Hunter RL, Elson CO. Strong mucosal adjuvanticity of cholera toxin within lipid particles of a new multiple emulsion delivery system for oral immunization. Eur. J. Immunol. 1997; 27:2720-2725. [PubMed: 9368632]

32. Clark SO, Kelly DLF, Badell E, Castello-Branco LR, Aldwell F, Winter N, Lewis DJM, Marsh PD. Oral delivery of BCG Moreau Rio de Janeiro gives equivalent protection against tuberculosis but with reduced pathology compared to parenteral BCG Danish vaccination. Vaccine. 2010; 28:7109-7116. [PubMed: 20708695]

33. Silin DS, Lyubomska OV, Jirathitikal V, Bourinbaiar AS. Oral vaccination: where we are? Expert Opin Drug Deliv. 2007; 4:323-340. [PubMed: 17683247] 
34. Hashimoto M, Takada K, Kiso Y, Muranishi S. Synthesis of palmitoyl derivatives of insulin and their biological activities. Pharm. Res. 1989; 6:171-176. [PubMed: 2668914]

35. Cheng W, Satyanarayanajois S, Lim L-Y. Aqueous-Soluble, Non-Reversible Lipid Conjugate of Salmon Calcitonin: Synthesis, Characterization and In Vivo Activity. Pharm Res. 2006; 24:99_ 110. [PubMed: 17109213]

36. Cheng W, Lim L-Y. Synthesis, characterization and in vivo activity of salmon calcitonin coconjugated with lipid and polyethylene glycol. J Pharm Sci. 2009; 98:1438-1451. [PubMed: 18704953]

37. al-Obeidi F, Hruby VJ, Yaghoubi N, Marwan MM, Hadley ME. Synthesis and biological activities of fatty acid conjugates of a cyclic lactam alpha-melanotropin. J. Med. Chem. 1992; 35:118-123. [PubMed: 1732518]

38. Kocevar N, Obermajer N, Strukelj B, Kos J, Kreft S. Improved acylation method enables efficient delivery of functional palmitoylated cystatin into epithelial cells. Chem Biol Drug Des. 2007; 69:124-131. [PubMed: 17381726]

39. Kocevar N, Obermajer N, Kreft S. Membrane permeability of acylated cystatin depends on the fatty acyl chain length. Chem Biol Drug Des. 2008; 72:217-224. [PubMed: 18702630]

40. Kratz F. Albumin as a drug carrier: design of prodrugs, drug conjugates and nanoparticles. J Control Release. 2008; 132:171-183. [PubMed: 18582981]

41. Varshney A, Sen P, Ahmad E, Rehan M, Subbarao N, Khan RH. Ligand binding strategies of human serum albumin: how can the cargo be utilized? Chirality. 2010; 22:77-87. [PubMed: 19319989]

42. Hussain R, Siligardi G. Novel drug delivery system for lipophilic therapeutics of small molecule, peptide-based and protein drugs. Chirality. 2010; 22(Suppl 1):E44-E46. [PubMed: 20872606]

43. Andersen JT, Sandlie I. The versatile MHC class I-related FcRn protects IgG and albumin from degradation: implications for development of new diagnostics and therapeutics. Drug Metab. Pharmacokinet. 2009; 24:318-332. [PubMed: 19745559]

44. van der Vusse GJ. Albumin as fatty acid transporter. Drug Metab. Pharmacokinet. 2009; 24:300307. [PubMed: 19745557]

45. Bhattacharya AA, Grüne T, Curry S. Crystallographic analysis reveals common modes of binding of medium and long-chain fatty acids to human serum albumin. J. Mol. Biol. 2000; 303:721-732. [PubMed: 11061971]

46. Spector AA. Fatty acid binding to plasma albumin. J. Lipid Res. 1975; 16:165-179. [PubMed: 236351]

47. Curry S, Mandelkow H, Brick P, Franks N. Crystal structure of human serum albumin complexed with fatty acid reveals an asymmetric distribution of binding sites. Nat Struct Mol Biol. 1998; 5:827-835.

48. Simard JR, Zunszain PA, Ha C-E, Yang JS, Bhagavan NV, Petitpas I, Curry S, Hamilton JA. Locating high-affinity fatty acid-binding sites on albumin by $\mathrm{x}$-ray crystallography and NMR spectroscopy. Proc. Natl. Acad. Sci. U.S.A. 2005; 102:17958-17963. [PubMed: 16330771]

49. Kurtzhals P. Pharmacology of insulin detemir. Endocrinol. Metab. Clin. North Am. 2007; 36(Suppl 1):14-20. [PubMed: 17881328]

50. Kurtzhals P, Havelund S, Jonassen I, Kiehr B, Larsen UD, Ribel U, Markussen J. Albumin binding of insulins acylated with fatty acids: characterization of the ligand-protein interaction and correlation between binding affinity and timing of the insulin effect in vivo. Biochem. J. 1995; 312(Pt 3):725-731. [PubMed: 8554512]

51. Choi J-K, Ho J, Curry S, Qin D, Bittman R, Hamilton JA. Interactions of very long-chain saturated fatty acids with serum albumin. J. Lipid Res. 2002; 43:1000-1010. [PubMed: 12091483]

52. Sørensen AR, Stidsen CE, Ribel U, Nishimura E, Sturis J, Jonassen I, Bouman SD, Kurtzhals P, Brand CL. Insulin detemir is a fully efficacious, low affinity agonist at the insulin receptor. Diabetes Obes Metab. 2010; 12:665-673. [PubMed: 20590743]

53. Elbrønd B, Jakobsen G, Larsen S, Agers $\varnothing$ H, Jensen LB, Rolan P, Sturis J, Hatorp V, Zdravkovic M. Pharmacokinetics, Pharmacodynamics, Safety, and Tolerability of a Single-Dose of NN2211, a Long-Acting Glucagon-Like Peptide 1 Derivative, in Healthy Male Subjects. Diabetes Care. 2002; 25:1398-1404. [PubMed: 12145241] 
54. Birkeland KI, Home PD, Wendisch U, Ratner RE, Johansen T, Endahl LA, Lyby K, Jendle JH, Roberts AP, Devries JH, Meneghini LF. Insulin Degludec in Type 1 Diabetes: A randomized controlled trial of a new-generation ultra-long-acting insulin compared with insulin glargine. Diabetes Care. 2011; 34:661-665. [PubMed: 21270174]

55. Heise T, Tack CJ, Cuddihy R, Davidson J, Gouet D, Liebl A, Romero E, Mersebach H, Dykiel P, Jorde R. A New-Generation Ultra-Long-Acting Basal Insulin With a Bolus Boost Compared With Insulin Glargine in Insulin-Naive People With Type 2 Diabetes: A randomized, controlled trial. Diabetes Care. 2011; 34:669-674. [PubMed: 21285389]

56. Mariko, M.; Park, K. Applications and Clinical Development. 1st ed.. Informa Healthcare; 2009. Biodrug Delivery Systems: Fundamentals.

57. Ekrami HM, Kennedy AR, Shen W-C. Water-soluble fatty acid derivatives as acylating agents for reversible lipidization of polypeptides. FEBS Letters. 1995; 371:283-286. [PubMed: 7556611]

58. Wang J, Hogenkamp DJ, Tran M, Li W-Y, Yoshimura RF, Johnstone TBC, Shen W-C, Gee KW. Reversible lipidization for the oral delivery of leu-enkephalin. J Drug Target. 2006; 14:127-136. [PubMed: 16753826]

59. Yuan L, Wang J, Shen W-C. Reversible Lipidization Prolongs the Pharmacological Effect, Plasma Duration, and Liver Retention of Octreotide. Pharm Res. 2005; 22:220-227. [PubMed: 15783069]

60. Tsay W, Shen MC. Experience of desmopressin (DDAVP) administration in patients with congenital and acquired bleeding disorders. J. Formos. Med. Assoc. 1992; 91:962-969. [PubMed: 1362675]

61. Wang J, Shen D, Shen WC. Preparation, purification, and characterization of a reversibly lipidized desmopressin with potentiated anti-diuretic activity. Pharm. Res. 1999; 16:1674-1679. [PubMed: 10571271]

62. Wang J, Chow D, Heiati H, Shen WC. Reversible lipidization for the oral delivery of salmon calcitonin. J Control Release. 2003; 88:369-380. [PubMed: 12644363]

63. Yuan L, Wang J, Shen W-C. Lipidization of human interferon-alpha: a new approach toward improving the delivery of protein drugs. J Control Release. 2008; 129:11-17. [PubMed: 18448186]

64. Honeycutt L, Wang J, Ekrami H, Shen WC. Comparison of pharmacokinetic parameters of a polypeptide, the Bowman-Birk protease inhibitor (BBI), and its palmitic acid conjugate. Pharm. Res. 1996; 13:1373-1377. [PubMed: 8893277]

65. Wang J, Wu D, Shen W-C. Structure-activity relationship of reversibly lipidized peptides: studies of fatty acid-desmopressin conjugates. Pharm. Res. 2002; 19:609-614. [PubMed: 12069162]

66. Asada H, Douen T, Waki M, Adachi S, Fujita T, Yamamoto A, Muranishi S. Absorption characteristics of chemically modified-insulin derivatives with various fatty acids in the small and large intestine. J Pharm Sci. 1995; 84:682-687. [PubMed: 7562404]

67. Fujita T, Kawahara I, Quan Y, Hattori K, Takenaka K, Muranishi S, Yamamoto A. Permeability characteristics of tetragastrins across intestinal membranes using the Caco-2 monolayer system: comparison between acylation and application of protease inhibitors. Pharm. Res. 1998; 15:13871392. [PubMed: 9755890]

68. Uchiyama T, Kotani A, Tatsumi H, Kishida T, Okamoto A, Okada N, Murakami M, Fujita T, Fujiwara Y, Kiso Y, Muranishi S, Yamamoto A. Development of novel lipophilic derivatives of DADLE (leucine enkephalin analogue): intestinal permeability characateristics of DADLE derivatives in rats. Pharm. Res. 2000; 17:1461-1467. [PubMed: 11303954]

69. Cheng W, Lim L-Y. Comparison of Reversible and Nonreversible Aqueous-Soluble Lipidized Conjugates of Salmon Calcitonin. Mol. Pharmaceutics. 2008; 5:610-621.

70. Cheng W, Lim L-Y. Lipeo-sCT: a novel reversible lipidized salmon calcitonin derivative, its biophysical properties and hypocalcemic activity. Eur J Pharm Sci. 2009; 37:151-159. [PubMed: 19429422]

71. Mao, S.; Cun, D.; Kawashima, Y. Novel Non-Injectable Formulation Approaches of Peptides and Proteins. In: Jorgensen, L.; Nielsen, HM., editors. Delivery Technologies for Biopharmaceuticals. John Wiley \& Sons, Ltd, n.d.; p. 29-67.

72. Morishita M, Peppas NA. Is the oral route possible for peptide and protein drug delivery? Drug Discov. Today. 2006; 11:905-910. [PubMed: 16997140] 
73. Shen W-C. Oral peptide and protein delivery: unfulfilled promises? Drug Discovery Today. 2003; 8:607-608. [PubMed: 12867138]

74. Hevonoja T, Pentikäinen MO, Hyvönen MT, Kovanen PT, Ala-Korpela M. Structure of low density lipoprotein (LDL) particles: basis for understanding molecular changes in modified LDL. Biochim. Biophys. Acta. 2000; 1488:189-210. [PubMed: 11082530]

75. Teerlink T, Scheffer PG, Bakker SJL, Heine RJ. Combined Data from LDL Composition and Size Measurement Are Compatible with a Discoid Particle Shape. J. Lipid Res. 2004; 45:954-966. [PubMed: 14967822]

76. Kratz F, Beyer U. Serum proteins as drug carriers of anticancer agents: a review. Drug Deliv. 1998; 5:281-299. [PubMed: 19569996]

77. Alaupovic P. Significance of apolipoproteins for structure, function, and classification of plasma lipoproteins. Meth. Enzymol. 1996; 263:32-60. [PubMed: 8748999]

78. Goudriaan JR, Espirito Santo SMS, Voshol PJ, Teusink B, van Dijk KW, van Vlijmen BJM, Romijn JA, Havekes LM, Rensen PCN. The VLDL receptor plays a major role in chylomicron metabolism by enhancing LPL-mediated triglyceride hydrolysis. J. Lipid Res. 2004; 45:14751481. [PubMed: 15145981]

79. Wasan KM, Brocks DR, Lee SD, Sachs-Barrable K, Thornton SJ. Impact of lipoproteins on the biological activity and disposition of hydrophobic drugs: implications for drug discovery. Nat Rev Drug Discov. 2008; 7:84-99. [PubMed: 18079757]

80. Hamidi M, Foroozesh M, Zarrin A. Lipoproteins: from physiological roles to drug delivery potentials. Crit Rev Ther Drug Carrier Syst. 2006; 23:497-523. [PubMed: 17425501]

81. Edwards IJ, Berquin IM, Sun H, O’Flaherty JT, Daniel LW, Thomas MJ, Rudel LL, Wykle RL, Chen YQ. Differential Effects of Delivery of Omega-3 Fatty Acids to Human Cancer Cells by Low-Density Lipoproteins versus Albumin. Clinical Cancer Research. 2004; 10:8275-8283. [PubMed: 15623603]

82. Wolfrum C, Shi S, Jayaprakash KN, Jayaraman M, Wang G, Pandey RK, Rajeev KG, Nakayama T, Charrise K, Ndungo EM, Zimmermann T, Koteliansky V, Manoharan M, Stoffel M. Mechanisms and optimization of in vivo delivery of lipophilic siRNAs. Nat Biotech. 2007; 25:1149-1157.

83. Atkinson D, Small DM. Recombinant lipoproteins: implications for structure and assembly of native lipoproteins. Annu Rev Biophys Biophys Chem. 1986; 15:403-456. [PubMed: 3521660]

84. Murakami T, Wijagkanalan W, Hashida M, Tsuchida K. Intracellular drug delivery by genetically engineered high-density lipoprotein nanoparticles. Nanomedicine (Lond). 2010; 5:867-879. [PubMed: 20735223]

85. Zurita AJ, Troncoso P, Cardó-Vila M, Logothetis CJ, Pasqualini R, Arap W. Combinatorial screenings in patients: the interleukin-11 receptor alpha as a candidate target in the progression of human prostate cancer. Cancer Res. 2004; 64:435-439. [PubMed: 14744752]

86. Lewis VO, Ozawa MG, Deavers MT, Wang G, Shintani T, Arap W, Pasqualini R. The interleukin-11 receptor alpha as a candidate ligand-directed target in osteosarcoma: consistent data from cell lines, orthotopic models, and human tumor samples. Cancer Res. 2009; 69:1995-1999. [PubMed: 19244100]

87. Blanckaert V, Ulmann L, Mimouni V, Antol J, Brancquart L, Chénais B. Docosahexaenoic acid intake decreases proliferation, increases apoptosis and decreases the invasive potential of the human breast carcinoma cell line MDA-MB-231. Int. J. Oncol. 2010; 36:737-742. [PubMed: 20126994]

88. Lee CY-K, Sit W-H, Fan S-T, Man K, Jor IW-Y, Wong LL-Y, Wan ML-Y, Tan-Un KC, Wan JMF. The cell cycle effects of docosahexaenoic acid on human metastatic hepatocellular carcinoma proliferation. Int. J. Oncol. 2010; 36:991-998. [PubMed: 20198345]

89. Habermann N, Christian B, Luckas B, Pool-Zobel BL, Lund EK, Glei M. Effects of fatty acids on metabolism and cell growth of human colon cell lines of different transformation state. Biofactors. 2009; 35:460-467. [PubMed: 19798733]

90. Zhang X, Chen B. Recombinant high density lipoprotein reconstituted with apolipoprotein AI cysteine mutants as delivery vehicles for 10-hydroxycamptothecin. Cancer Letters. 2010; 298:2633. [PubMed: 20579804] 
91. Nikanjam M, Blakely EA, Bjornstad KA, Shu X, Budinger TF, Forte TM. Synthetic nano-low density lipoprotein as targeted drug delivery vehicle for glioblastoma multiforme. Int J Pharm. 2007; 328:86-94. [PubMed: 16959446]

92. Nikanjam M, Gibbs AR, Hunt CA, Budinger TF, Forte TM. Synthetic nano-LDL with paclitaxel oleate as a targeted drug delivery vehicle for glioblastoma multiforme. J Control Release. 2007; 124:163-171. [PubMed: 17964677]

93. Ross R. The pathogenesis of atherosclerosis: a perspective for the 1990s. Nature. 1993; 362:801809. [PubMed: 8479518]

94. Wang X, Greilberger J, Ratschek M, Jürgens G. Oxidative modifications of LDL increase its binding to extracellular matrix from human aortic intima: influence of lesion development, lipoprotein lipase and calcium. J. Pathol. 2001; 195:244-250. [PubMed: 11592105]

95. Tauchi Y, Zushida L, Yokota M, Chono S, Sato J, Ito K, Morimoto K. Inhibitory effect of dexamethasone palmitate-low density lipoprotein complex on low density lipoprotein-induced macrophage foam cell formation. Biol. Pharm. Bull. 2000; 23:466-471. [PubMed: 10784429]

96. Tauchi Y, Zushida L, Chono S, Sato J, Ito K, Morimoto K. Effect of dexamethasone palmitate-low density lipoprotein complex on cholesterol ester accumulation in aorta of atherogenic model mice. Biol. Pharm. Bull. 2001; 24:925-929. [PubMed: 11510487]

97. Rodrigues DG, Maria DA, Fernandes DC, Valduga CJ, Couto RD, Ibañez OCM, Maranhão RC. Improvement of paclitaxel therapeutic index by derivatization and association to a cholesterol-rich microemulsion: in vitro and in vivo studies. Cancer Chemother. Pharmacol. 2005; 55:565-576. [PubMed: 15726368]

98. Ishida T, Kiwada H. Accelerated blood clearance (ABC) phenomenon upon repeated injection of PEGylated liposomes. Int J Pharm. 2008; 354:56-62. [PubMed: 18083313]

99. Ishida T, Wang X, Shimizu T, Nawata K, Kiwada H. PEGylated liposomes elicit an anti-PEG IgM response in a T cell-independent manner. J Control Release. 2007; 122:349-355. [PubMed: 17610982]

100. Yoo J-W, Irvine DJ, Discher DE, Mitragotri S. Bio-inspired, bioengineered and biomimetic drug delivery carriers. Nature Reviews Drug Discovery. 2011; 10:521-535.

101. Bhattacharya A. Red blood cell mechanics. J Indian Med Assoc. 2011; 109:668-670. 682. [PubMed: 22480103]

102. Luo R, Mutukumaraswamy S, Venkatraman SS, Neu B. Engineering of erythrocyte-based drug carriers: control of protein release and bioactivity. J Mater Sci Mater Med. 2012; 23:63-71. [PubMed: 22095447]

103. Wu J, Yang S, Luo H, Zeng L, Ye L, Lu Y. Quantitative evaluation of monocyte transmigration into the brain following chemical opening of the blood-brain barrier in mice. Brain Res. 2006; 1098:79-85. [PubMed: 16908012]

104. Suh D-C, Aagren M. Cost-effectiveness of insulin detemir: a systematic review. Expert Rev Pharmacoecon Outcomes Res. 2011; 11:641-655. [PubMed: 21961796]

105. Stehle G, Sinn H, Wunder A, Schrenk HH, Stewart JC, Hartung G, Maier-Borst W, Heene DL. Plasma protein (albumin) catabolism by the tumor itself--implications for tumor metabolism and the genesis of cachexia. Crit. Rev. Oncol. Hematol. 1997; 26:77-100. [PubMed: 9298326]

106. Cantafora A, Blotta I. Neutral lipids production, transport, utilization. Anticancer Res. 1996; 16:1441-1449. [PubMed: 8694512]

107. Kratz F. DOXO-EMCH (INNO-206): the first albumin-binding prodrug of doxorubicin to enter clinical trials. Expert Opin Investig Drugs. 2007; 16:855-866.

108. Elsadek B, Graeser R, Esser N, Schäfer-Obodozie C, Ajaj KA, Unger C, Warnecke A, Saleem T, El-Melegy N, Madkor H, Kratz F. Development of a novel prodrug of paclitaxel that is cleaved by prostate-specific antigen: an in vitro and in vivo evaluation study. Eur. J. Cancer. 2010; 46:3434-3444. [PubMed: 20933385]

109. Abu Ajaj K, Graeser R, Kratz F. Zosuquidar and an albumin-binding prodrug of zosuquidar reverse multidrug resistance in breast cancer cells of doxorubicin and an albumin-binding prodrug of doxorubicin. Breast Cancer Research and Treatment. 2012 


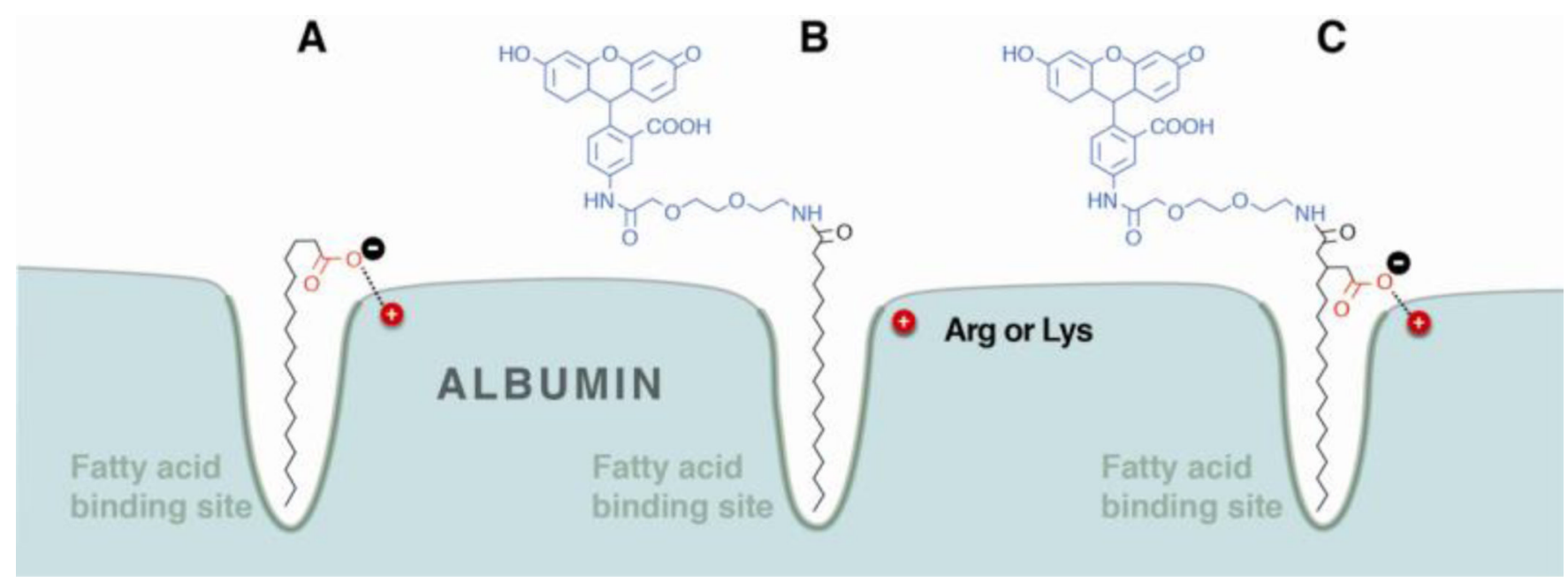

Figure 1.

A schematic presentation of the hydrophobic and electrostatic interactions involved in fatty acid-albumin binding (A). The addition of a drug, or surrogate such as fluoresceinamine (blue), may utilize only the hydrophobic interaction (B) or both hydrophobic and electrostatic (red) interactions (C) depending on the modification chemistry. 


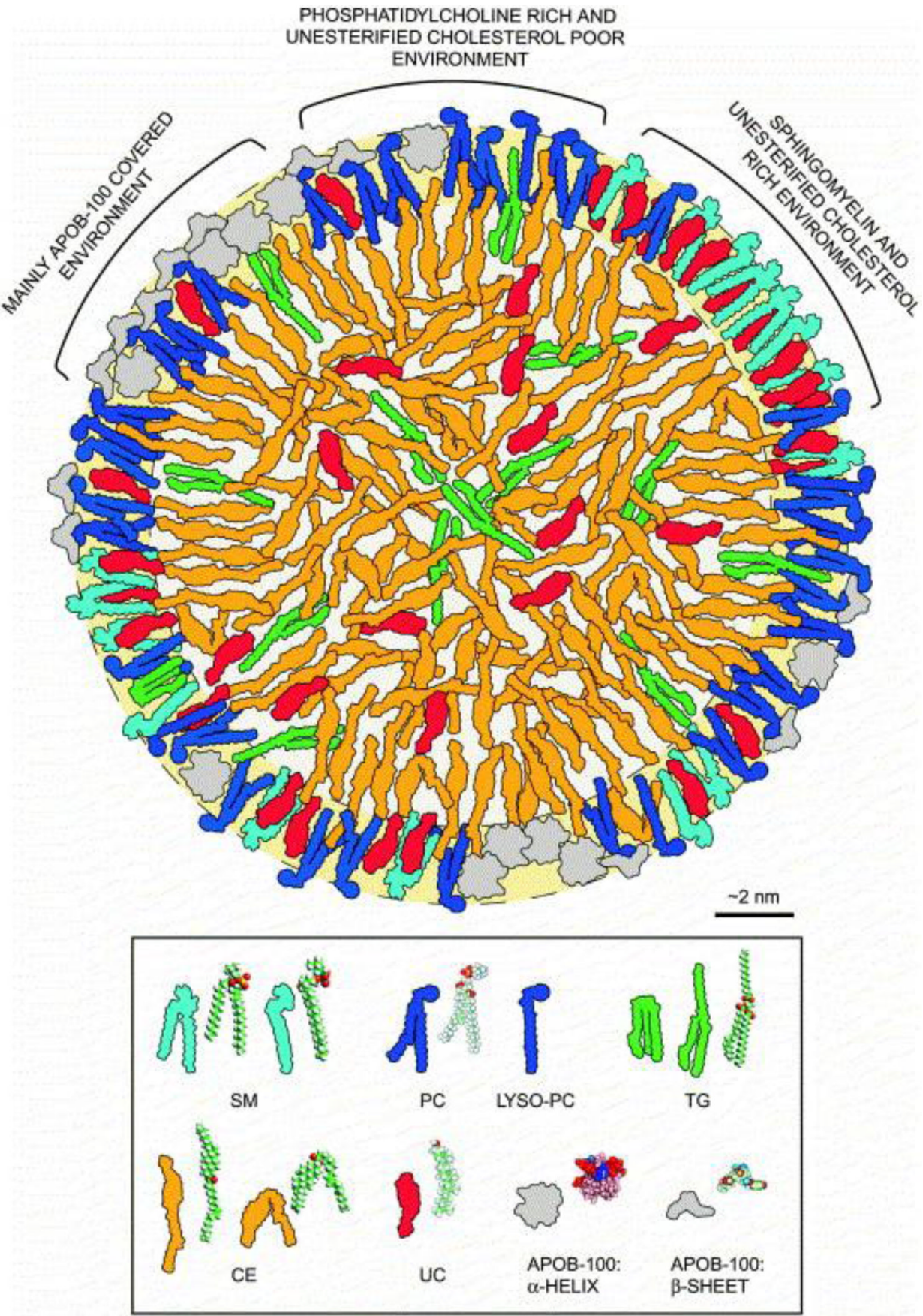

Figure 2.

Artwork depicting the LDL particle. The outer shell contains mostly triglyceride and free cholesterol while the internal core contains mostly cholesteryl ester with some triglyceride. The particle is held together by Apo-B100 which wraps around the particle equatorially. SM, sphingomyelin; PC, phosphatidylcholine; TG, triglyceride; CE, cholesteryl ester; UC, unesterified cholesterol. [Reprinted from, Biochimica et Biophysica Acta (BBA) -

Molecular and Cell Biology of Lipids, 1488, Tiia Hevonoja, Markku O Pentikäinen, Marja T Hyvönen, Petri T Kovanen, Mika Ala-Korpela, Structure of low density lipoprotein (LDL) particles: Basis for understanding molecular changes in modified LDL, 189-210, Copyright (2000), with permission from Elsevier] 


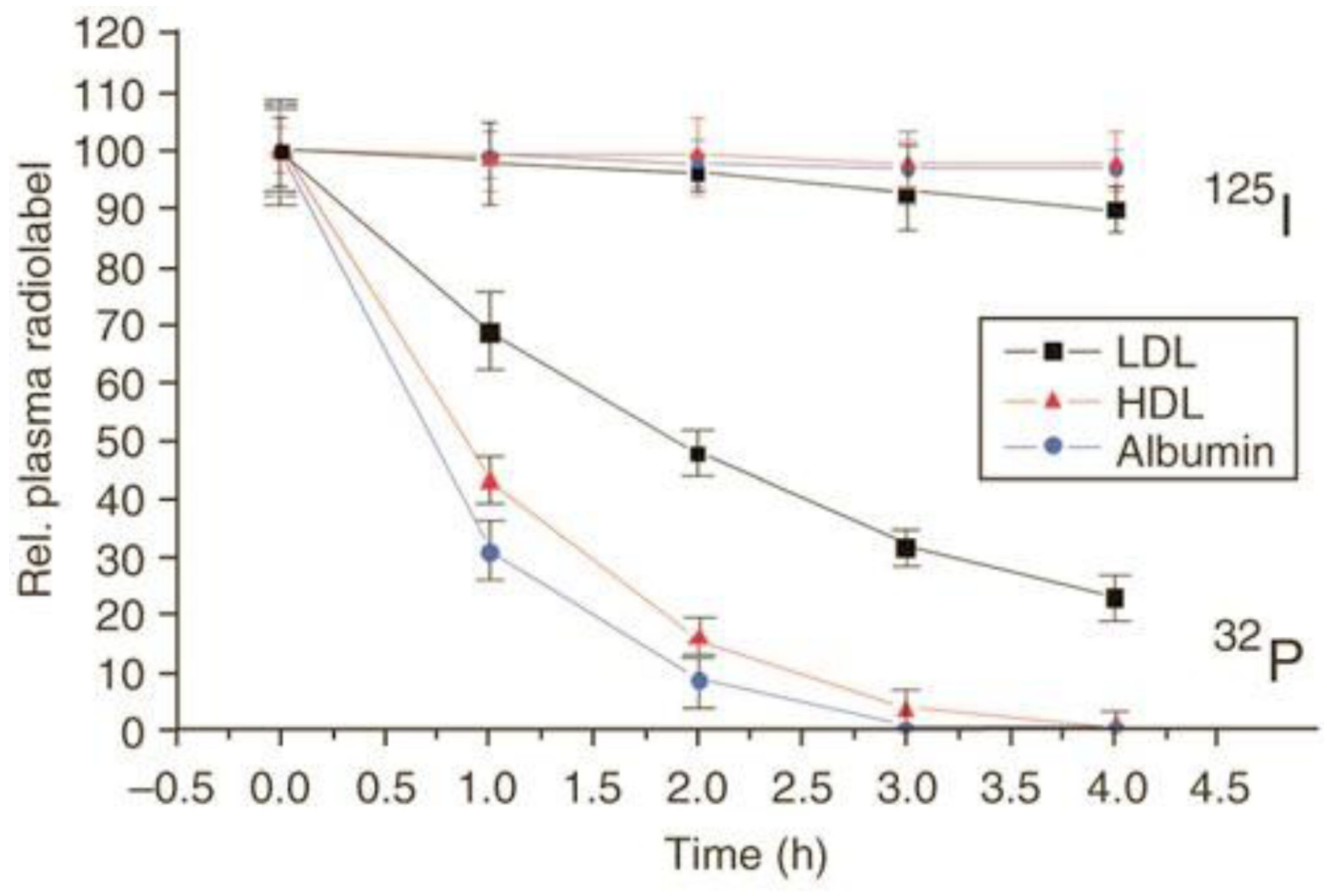

Figure 3.

The serum pharmacokinetics of a cholesterol derivative of ${ }^{32} \mathrm{P}$-labeled siRNA and various ${ }^{125}$ I-labeled serum components that are known to bind cholesterol. Note that the relatively weak binding of the cholesterol-esterified siRNA to the serum components resulted in a significantly different profile compared to the carriers alone. [Reprinted by permission from Macmillan Publishers Ltd: Nature Biotechnology [82], copyright (2007)] 


\section{Table 1}

Improved pharmacokinetic properties by reversible lipidization with palmitic acid.

\begin{tabular}{|c|c|c|c|c|}
\hline \multirow{2}{*}{ Lipidized peptide/protein } & \multirow{2}{*}{ Linkage } & \multirow{2}{*}{$\begin{array}{c}\text { Administration } \\
\text { route }\end{array}$} & & \multicolumn{2}{|c|}{ Fold increase (vs. non-lipidized) } \\
\cline { 5 - 5 } & & & $\mathbf{A U C}^{\boldsymbol{a}}$ & ${\text { Plasma } \mathbf{t}_{\mathbf{1} \mathbf{2}}}^{*}$ \\
\hline Bowman-Birk Protease Inhibitor [64] & Disulfide & i.v. & 11 & 2 \\
\hline Desmopressin [61] & Disulfide & i.v. & 7 & n.a. $^{b}$ \\
\hline Octreotide [59] & Disulfide & i.v. & 8 & 5 \\
\hline Interferon-a [63] & Disulfide & i.v. & n.a. & 5 \\
\hline Calcitonin [62] & Disulfide & s.c. & 4 & n.a. \\
\hline Calcitonin [62] & Disulfide & p.o. & 19 & n.a. \\
\hline Enkephalin [58] & pH-sensitive & p.o. & 21 & n.a. \\
\hline
\end{tabular}

${ }^{a} \mathrm{AUC}$, area under the concentration versus time curve

$b_{\text {n.a., data not available }}$ 